\title{
The evaluation of physical learning environments: a critical review of the literature
}

\author{
Benjamin Cleveland $\cdot$ Kenn Fisher
}

\begin{abstract}
This article critically reviews the methodologies and methods that have been used for the evaluation of physical learning environments. To contextualize discussion about the evaluation of learning spaces, we initially chart the development of post-occupancy evaluation (POE) for non-domestic buildings. We then discuss the recent evolution of POE into the broader evaluative framework of building performance evaluation. Subsequently, a selection of approaches used to evaluate higher education and school learning environments are compared and critically analyzed in view of contemporary approaches to teaching and learning. Gaps in these evaluative approaches are identified and an argument is put forward for the evaluation of physical learning environments from a more rigorous pedagogical perspective.
\end{abstract}

Keywords Contemporary education - Evaluation · Methodologies · Methods · Pedagogies · Physical learning environment · Post-occupancy evaluation

\section{Introduction}

The term 'learning environment' is regularly used to refer to the social, psychological or conceptual environment rather than to the physical learning environment or space (Cleveland 2009). Nevertheless, increasing numbers of both educators and design professionals are becoming aware of the important role that physical space plays in educational settings (Beare 2000; Buckley et al. 2005; Clarke 2001; Cleveland 2011; Edwards and Clarke 2002; Fisher 2004; Hartnell-Young 2006; Heppell et al. 2004; Higgins et al. 2005; Lackney 1999; Lippman 2007; Monahan 2005; Newton and Fisher 2009; Upitis 2010; Stevenson 2007; Taylor 2009; Wall et al. 2008; Weinstein 1979). Over the past few

B. Cleveland $(\square) \cdot$ K. Fisher

Faculty of Architecture, Building and Planning, The University of Melbourne, Parkville, VIC 3010,

Australia

e-mail: benjamin.cleveland@unimelb.edu.au 
decades, the collective works of human geographers, including Lefebvre (1991), Soja (1989), Massey $(1999,2005)$ and McGregor $(2004 a, b, c)$ have brought attention to the way in which space interacts and interrelates with the social world. In addition, Foucault's work on 'power-knowledge' and the influence of architecture on social power relationships has been highlighted by those working in the field (Flyvbjerg 1998; Hirst 2005; Joseph 2003). Subsequently, theorising of educational settings through the construct of spatiality- "the production of space through the interaction of the physical and the social" (McGregor 2004a, p. 2) - has shown how apparently innocent physical aspects of space actually participate in and mediate social relations. Such theorizing has begun to overcome what Fisher (2004) called a 'deep spatial silence' or 'unconsciousness' regarding the power of space and the influence it has over school organizational structures and learning. Based on these theoretical foundations, this literature review critically reviews the methodologies and methods that have been used for the evaluation of physical learning environments.

The authors recognise that learning environment research has often focused on social or psychosocial environments (Aldridge et al. 2012; Fraser and Walberg 1991; Moos 1979, 1987; Walker and Fraser 2005), rather than physical environments. The purpose of this literature review is to bring together some of the more prominent work on the evaluation of physical learning environments and to highlight opportunities and directions for future research in this domain.

The evaluation of physical learning environments has become an important issue with the recent development of new buildings in many developed countries that are intended to support contemporary approaches to teaching and learning (OECD 2009a). Because the trend towards creating resource and technology rich facilities (Dudek 2008; JISC 2006) is expensive, innovative school and higher education facilities require evaluation in order to ascertain what works and what doesn't work. This information could be valuable to a range of stakeholders, including architects, building owners and building users. The information gained through evaluation could inform new building projects or assist those occupying existing facilities who wish to get the most out of what they already have.

To contextualise discussion about the evaluation of educational spaces, this article initially charts the development of post-occupancy evaluation (POE) for non-domestic buildings and discusses its recent evolution into the broader evaluative framework of building performance evaluation (BPE). Subsequently, a selection of the methodologies and methods that have been used to evaluate educational buildings are critically analyzed to indentify which might be suitable for the evaluation of contemporary physical learning environments.

\section{Defining post-occupancy evaluation}

Post-occupancy evaluation has been defined in a number of ways. Zimring and Reizenstein (1980, p. 429) proposed that POE was "the examination of the effectiveness for human users of occupied designed environments". Preiser (2002, p. 42) defined POE as "a process of systematically evaluating the performance of buildings after they have been built and occupied for some time", and Hadjri and Crosier (2008, p. 22) defined POE as a "process that involves a rigorous approach to the assessment of both the technological and anthropological elements of a building in use". As yet, there remains no agreed definition for the process of POE.

Why post-occupancy evaluation?

The information collected through POEs can be valuable to a range of stakeholders across a building's life cycle (Hadjri and Crosier 2008). Zimmerman and Martin (2001) suggested 
that the information collected can be used to validate occupants' real needs, improve fit between occupants and their buildings, optimize services to suit occupants, reduce waste of space and energy, reduce ownership/operational expenses, and improve competitive advantage in the marketplace. In addition, Whyte and Gann (2001) suggested that POEs can support stakeholders in applying design skills more effectively, improving commissioning processes, improving user requirements, improving management procedures, providing knowledge for design guides and regulatory processes, and targeting refurbishment.

Information from POEs can also support the goal of continuous improvement by supporting decisions made during the programming and design stages of building projects (Zimmerman and Martin 2001). To this end, Zimmerman and Martin (2001) concluded:

There are valuable lessons to be learned from occupants about space in use which can be used to improve existing spaces and inform the programming of future buildings... without a feedback loop, every building is, to some extent, a prototype spaces and systems put together in new ways, with potentially unpredictable outcomes. (p. 169)

Thus, feedback from building evaluations could add value to the next building project by reducing the need to make decisions based on assumptions about how organizations are likely to function and about how people are likely to use space.

\section{Evolution of post-occupancy evaluation}

\section{Origins of systematic building evaluation}

The first systematic building evaluations were conducted during the 1960s (Cooper 2001; Preiser and Nasar 2008). These early evaluations were performed on university dormitories in the USA (Preiser and Nasar 2008) and on a variety of non-domestic buildings in the UK (Cooper 2001). In 1965, the Royal Institute of British Architects (RIBA) tried to establish POE as a fundamental service provided by architects in their 1965 Handbook. They suggested a 'plan of work' that included 'Stage M: Feedback' (Cooper 2001). However, this initiative was short lived and POE studies in the late 1960s were not often linked to architectural practices. More commonly, they were conducted by academic researchers with backgrounds in environmental psychology who were interested in the interaction of people and their environment and wished to "make building design more rigorous and systematic" (Cooper 2001, p. 159).

During the 1980s, many building evaluations were carried out on public works projects and government buildings in the UK, USA, Canada, New Zealand and Australia (Preiser and Nasar 2008). These POEs were implemented differently in different countries because of varied cultural contexts and differing perspectives on building evaluation. This led to a proliferation of POE methodologies (Hadjri and Crosier 2008). Hadjri and Crosier (2008) proposed the following reason for the development of these differing approaches:

An explanation for this mutability is most likely due to the complex and dynamic relationship that humans have with their built environment. From a research perspective, POE can be explored architecturally, though it may also be equally explored within the realms of psychology and sociology. 
POE fell from favour during the late 1980s because of a perception that the lens of environmental psychology had failed to deliver because of a disconnection between the commitment to measurement and involvement in the consequences of those measurements. However, POE was 'rescued' by the emerging discipline of facilities management in the early 1990s (Cooper 2001). Cooper correlated the interest of facility managers in POE with their focus on the needs of occupants.

During the 2000s, POE again caught the attention of academic researchers. Preiser and Nasar (2008) attributed renewed interest in building evaluation to the development of a new perspective from which to consider building evaluations:

The 21 st century has seen a new paradigm replacing the hierarchical, command and control, top-down approach with a consumer-oriented democratic approach, one that is autonomous, self-organizing, ecological, to sustain adaptation and continuous improvement... Nurturing and empathy replaces obedience and authoritarian solutions. It replaces design heroes with equality and bottom up evaluation. It calls for fairness, open, two-way communication, community building, cooperation, trust and honesty. For places experienced by the public (building exteriors, and interiors used by many people), the values of the public (the consumer) take priority. (pp. 88-89)

\section{Barriers to POE}

Researchers have suggested that POE methodologies have been beset with problems because the multidisciplinary nature of building evaluation and the diverse interests of those involved, including academics, designers, planners, engineers, financiers, consultants, builders and users (Leaman et al. 2010; Zimring and Reizenstein 1980). In keeping with this assessment, Cooper (2001) concluded that the question of who 'owns' POE is important. He suggested that POE will remain 'stunted' until issues associated with who is undertaking POE and who is commissioning and paying for POE can be resolved. Cooper (2001) also identified the early influence of environmental psychology on POE as having left behind a legacy with both positive and negative traits:

Environmental psychology has had a lasting legacy for and impact on post-occupancy evaluation in the UK. At best, this spawned a strong focus on the systematic collection and analysis of empirical evidence. At worst, it ushered in a narrowly psycho-physical approach to the study of buildings in use, incapable of dealing maturely with social, economic, political or cultural factors. (p. 160)

Additional potential barriers to the development and widespread adoption of POE were identified by Vischer (2001): cost, defending professional integrity, time and skills. In addition, Turpin-Brooks and Viccars (2006) suggested that designers don't want to spend money on evaluation because it is generally not part of standard procurement procedures, and Hadji and Crosier (2008) suggested that professional liability and litigation also can act as barriers to building evaluations being carried out by architects. Finally, a lack of training for architects in how to conduct POEs could be acting as a barrier to the widespread adoption of POE. To this end, Preiser (2001) suggested that POE training should become embedded within the studio courses undertaken by architecture students so that they might become more familiar with methods of evaluation. 
From post-occupancy evaluation to building performance evaluation

New perspectives on building evaluation have supported the recent development of a more holistic approach to POE termed BPE. With regard to this, Hadjri and Crosier (2008) concluded that "POE has progressed from a one dimensional feedback process to a multidimensional process that, as an integrated element, can help drive the building procurement process forward". In this evaluation framework, POE represents only one of six internal review loops (see Fig. 1 below) (Preiser and Nasar 2008). Developed during the mid-1990s, BPE has a particular emphasis on feeding forward information gained through phased evaluation across a buildings' life-cycle into the next building cycle (Preiser and Vischer 2005).

Preiser and Vischer (2005, pp. 8-9) described the goal of BPE as follows:

To improve the quality of decisions made at every phase of the building life cycle, i.e. from strategic planning to programming, design and construction, all the way to facility management and adaptive reuse... This means that not only facilities, but also the forces that shape them (organizational, political, economic, social etc.) are taken into account.

In evaluating the influence of BPE, Leaman, Stevenson and Bordass (2010) suggested that evaluations of buildings using BPE have been relatively rare because of high cost. Nevertheless, they concluded that:

... nothing beats case studies of named buildings backed by thorough data collection, benchmarked against a national sample, finishing with a list of lessons learned, preferably including reflections on the results by the parties directly involved, and especially the design team (pp. 567-568).

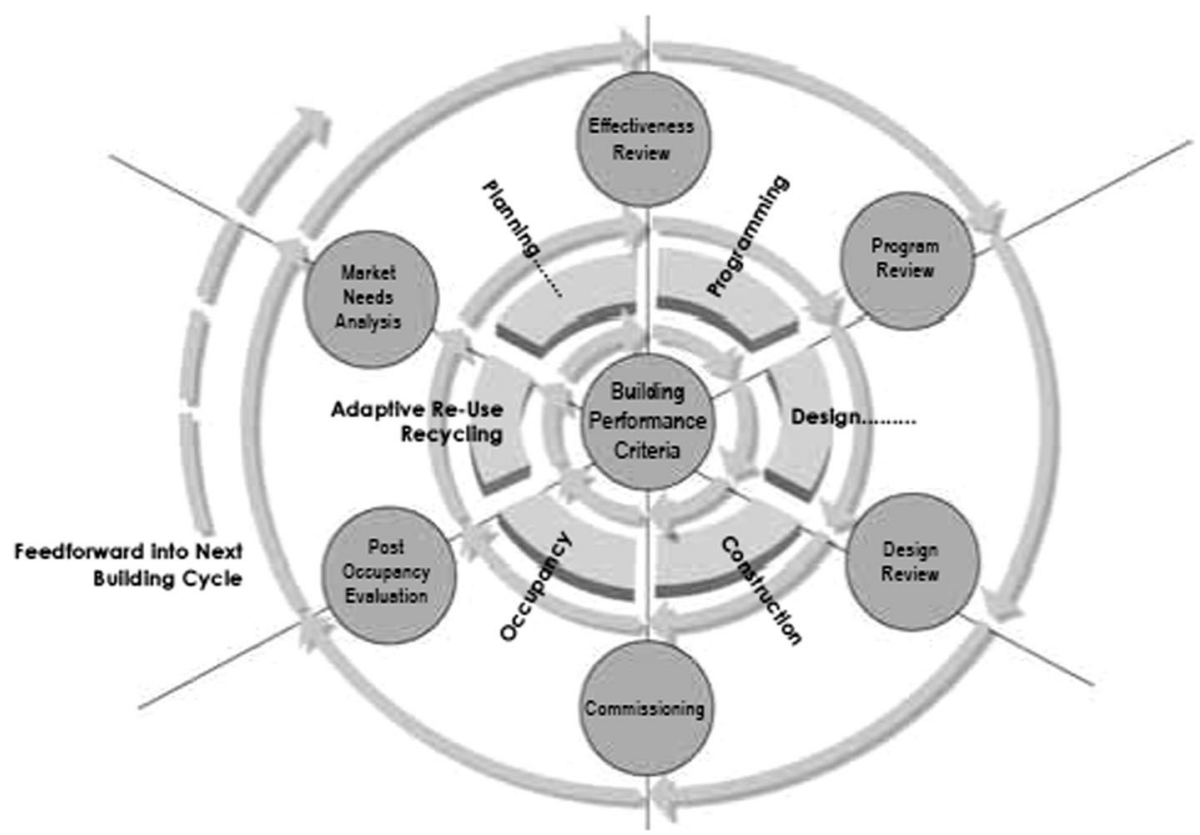

Fig. 1 Building performance evaluation (BPE) process model (Preiser and Nasar 2008, p. 90) 


\section{Post-occupancy evaluation methodologies and methods}

\section{Methodologies}

Preiser (1995) identified three general POE methodologies: indicative, investigative and diagnostic. He suggested that this range of evaluative approaches encompassed the full spectrum of projects from those investigating the finer points of a specific building, to the overall procurement program of a whole project, or a number of projects. He associated indicative POE with quick walk-through evaluations involving structured interviews with key personnel and group meetings with building users and inspections. Investigative POE, he suggested, involved more in-depth analyses involving interviews and questionnaires, usually across a number of buildings of the same or similar type. Diagnostic POE, he regarded as being the most sophisticated of the methodologies and likely to produce highly valid and generalisable research findings. He associated this approach with the evaluation of a number of comparable facilities from a broad range of technological and anthropological perspectives. Furthermore, he suggested that such research had the "potential of being transformed into guidelines" (Preiser 1995, p. 53).

In support of 'diagnostic' approaches to building evaluation, Zimring and Reizenstein (1980) suggested that longitudinal studies of multiple settings were the most desirable, although also the most expensive, and Turpin-Brooks and Viccars (2006) concluded that such approaches were desirable because they provided opportunity to engage in evaluation from a range of perspectives, including those associated with psycho-spatial issues, organisation/business needs, the perceptions of building users, the economic evaluation of productivity/environmental changes, and comparative 'scientific' data analysis (such as generated by environmental monitoring).

Data collection methods

With regard to data-collection methods, researchers have suggested that building evaluations require the collection of data using multiple methods to ensure that the weaknesses of some methods can be compensated for by the strengths of others (Turpin-Brooks and Viccars 2006; Zimring and Reizenstein 1980). It has also been recognised that building evaluations are often required within tight timeframes and that temporal constraints can influence the choice of methods used (Zimring and Reizenstein 1980).

With these potential limitations in mind, Zimring and Reizenstein (1980) recommended the following data-collection methods: interviews, checklists, questionnaires, systematic observation, participant observation, critical incidents and archival record analysis. Thirty years later, Leaman et al. (2010) suggested a similar, but updated, set of potentially useful methods, including: expert walk-throughs; measuring technical performance of building fabric, services and systems; assessing environmental performance; occupant survey questionaries; structured discussion interviews with participants; and visually recording matters related to the above points (photos, video, thermo-graphic images). In a departure from these methods, Zeisel (2006) championed a method of systematically observing the physical traces that people leave behind. He suggested that such observations allow environment-behaviour researchers to "infer how an environment got to be the way it is, what decisions its designers and builders made about the place, how people actually use it, [and] how they feel towards their surroundings" (p. 89). Leaman et al. (2010) also recommended that people be given the opportunity to expand on the categories covered. Furthermore, they suggested that 'drill down' approaches be utilised so that the issues 
raised can be followed up, that data be benchmarked against empirical evidence when possible, and that the context and circumstances surrounding a building evaluation be described fully as part of the process.

In response to the potential for excessive quantities of data to be collected, Cohen et al. (2001) recommended that the amount of time needed to both collect and analyse building evaluation data be carefully considered when selecting or designing building evaluation tools. In particular, they warned against collecting too much data for it to be meaningfully analysed.

\section{Presenting evaluation reports}

Finally, with regard to the presentation of building evaluation data and findings, Zimring and Reizenstein (1980) recommended that POE reports should be clearly presented, as the appearance of a building evaluation report is likely to influence whether or not various stakeholders will act on the information. In the following section, a number of the issues raised above regarding the evaluation of non-domestic buildings in general are discussed in connection with the evaluation of physical learning environments.

\section{Learning environment evaluation in education}

During the past decade new educational buildings have been developed in many developed countries (OECD 2009a) in response to changing perspectives on what constitutes important and appropriate education for school and higher education students in contemporary society. Renewed interest in progressive and constructivist approaches to education have encouraged people to re-examine their assumptions not only about educational provision across all sectors, but also about how best to design and use space for pedagogical activities (Cleveland 2009, 2011; Fisher 2002, 2004, 2005; Jamieson et al. 2005; Radcliffe et al. 2008). Interest in pedagogies that have been informed by the notions associated with experiential learning (Dewey 1966, 1971), critical pedagogy (Friere 1970), situated learning (Lave and Wenger 1991), authentic learning (Newmann 1992), interdisciplinary learning (Beare 2000) and the development of democratic citizens (McLaren 2007) has began to reframe people's attitudes towards the spaces in which students learn.

The trend towards creating resource-rich and technology-rich facilities (Dudek 2008; JISC 2006) is in its infancy. Therefore, there are few published evaluations of contemporary educational facilities that take into account the effectiveness of their design as pedagogical settings. Some exceptions to this include building evaluation studies of school buildings by Roberts (2008), Ornstien et al. (2009) and Zhang and Barrett (2010) and a collection of higher education facility evaluations published in Learning Spaces in Higher Education: Positive Outcomes by Design (Radcliffe et al. 2008).

The need for learning environment evaluation stems from a desire to collect evidence that can inform future decisions. Information gained through building evaluation could be used to inform decisions about both the design and the use of learning environments. For example, the evaluation of new building typologies could inform architects about the effectiveness of new design patterns, while simultaneously informing teachers and students about how they might best utilize new environments to support their pedagogical objectives. 
Shifting approaches to physical learning environment evaluation

In the following sections, we discuss a selection of research projects that have investigated learning environment evaluation in higher education and a sample of tools that have been used to evaluate school learning environments.

The review of the higher education literature, in particular, reveals a burgeoning interest in sociological and psychological evaluations that assess the influences of physical learning environments on the behaviours, practices and activities of occupants (lecturers and students). In contrast, with technical evaluations which focus on the qualities of the physical environment itself, renewed interest in evaluation at the intersection of the physical and the social represents a return to the origins of POE in environmental psychology. This burgeoning perspective on learning environment evaluation appears to be in keeping with Preiser and Nasar's (2008) suggestion that 'bottom up' approaches to evaluation, which value the opinions of the user and call for "open, two-way communication, community building, cooperation, trust and honesty" (p. 88), are currently being developed in education.

The conclusions of the Learning Landscapes in Higher Education report (CERD 2010) support this notion. This report concluded that evaluation should move from "a focus on 'spaces' to 'places' with an emphasis on the social and pedagogic rather than the financial and the material; as well as the development of outputs that are more relevant to the academic community than cost-based measures" (p. 47). In keeping with these notions, Hunley and Schaller (2006) suggested that higher education requires well-designed assessments that can provide the information needed to confirm the impact of learning spaces on learning. They suggested that this process must account for the complex interaction among learning spaces, pedagogical practices and student outcomes.

\section{Learning environment evaluation in higher education}

In this section, a number of research projects that have dealt with the evaluation of learning environments in higher education are critically reviewed. This review reveals that researchers have recently generated frameworks that are intended to support the development of tailored evaluation approaches, rather than produce generic evaluation tools that can be applied across a range of different spaces. This trend follows a growing recognition that approaches to physical learning environment evaluation in higher education need to be context specific. The findings of this review suggest that the use of generic evaluation tools could be inappropriate for evaluating the learning environments in higher education because of the diverse purposes and designs of these spaces and their diverse cultural settings.

Guide to post-occupancy evaluation

In 2006, the Higher Education Funding Council for England (HEFCE) produced a Guide to Post Occupancy Evaluation. This guide was intended to support evaluations across three broad areas: process, functional performance and technical performance (see Tables 1, 2, 3 for details below). Rather than outline any one approach to the evaluation of higher education learning environments, this guide provided a framework that allowed users to tailor context-specific evaluation strategies. This approach was adopted to ensure that different interpretations and purposes of POE could be accommodated. 
Table 1 Areas covered in a process evaluation (HEFCE 2006, p. 11)

\begin{tabular}{ll}
\hline Area & Examples \\
\hline Brief & $\begin{array}{c}\text { The way in which the team developed the brief on which the design was based } \\
\text { including financial management aspects } \\
\text { The way in which the team selection, contractual and technical processes were } \\
\text { undertaken including time and value aspects }\end{array}$ \\
$\begin{array}{l}\text { Procurement } \\
\text { The way in which the construction phase until handover was managed, including } \\
\text { financial and change management processes }\end{array}$ \\
$\begin{array}{l}\text { The way in which the final commissioning of the building was managed, including } \\
\text { process } \\
\text { final adjustments and the provision of documentation }\end{array}$ \\
$\begin{array}{l}\text { The way in which the handover process was managed including the rectification of } \\
\text { last-minute snags and the removal/relocation process }\end{array}$ \\
\hline
\end{tabular}

Table 2 Areas covered in a functional performance evaluation (HEFCE 2006, p. 11)

\begin{tabular}{ll}
\hline Area & Examples \\
\hline $\begin{array}{l}\text { Strategic value } \\
\begin{array}{l}\text { Aesthetics and } \\
\text { image }\end{array}\end{array}$ & $\begin{array}{l}\text { Achievement of original business objectives } \\
\text { Harmonious, neutral, iconic, powerful, bland }\end{array}$ \\
$\begin{array}{l}\text { Space } \\
\text { Comfort }\end{array}$ & $\begin{array}{l}\text { Size, relationships, adaptability } \\
\text { Environmental aspects: lighting, temperature, ventilation, noise, user control } \\
\text { Serviceability }\end{array}$ \\
$\begin{array}{l}\text { Operational costs } \\
\text { Cleaning, routine maintenance, security, essential changes }\end{array}$ \\
$\begin{array}{l}\text { Energy cost, water and waste, leases, cleaning, insurances } \\
\text { Initial construction cost, cost of operating, maintenance and repairs, replacement } \\
\text { costs, alterations, demolition }\end{array}$ \\
$\begin{array}{l}\text { Operational } \\
\text { management }\end{array}$ & training \\
\hline
\end{tabular}

Table 3 Areas covered in a technical performance evaluation (HEFCE 2006, p. 12)

\begin{tabular}{ll}
\hline Area & Examples \\
\hline $\begin{array}{l}\text { Physical systems } \\
\begin{array}{l}\text { Environmental } \\
\text { systems }\end{array}\end{array}$ & $\begin{array}{l}\text { Lighting, heating, ventilation, acoustics } \\
\text { Energy consumption, water consumption, } \mathrm{CO}_{2} \text { output } \\
\begin{array}{l}\text { Adaptability } \\
\text { Durability }\end{array}\end{array}$ \\
$\begin{array}{l}\text { Ability to accommodate change } \\
\text { Robustness, need for routine extensive maintenance, incidence of 'down time' for } \\
\text { unplanned technical reasons }\end{array}$ \\
\hline
\end{tabular}

The guide suggested a seven step process to developing a tailored approach: identify POE strategy; decide which approach; brief for the POE; plan the POE (if being carried out internally); carry out the POE; prepare the report; and action in response to POE. It also provided advice regarding: when it was appropriate to conduct different forms of evaluation during a building's lifecycle; the types of indicators that might be used for evaluation; suitable timeframes for evaluation; and details regarding a variety of data-collection methods. 


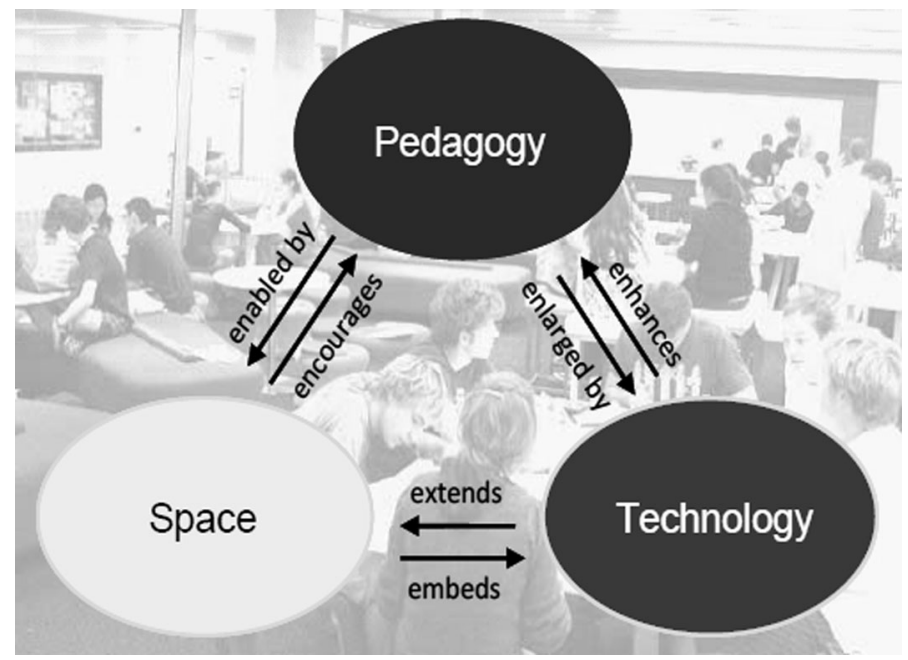

Fig. 2 A Pedagogy-Space-Technology framework for designing and evaluating learning spaces (Radcliffe 2008, p. 13)

Learning spaces in higher education: positive outcomes by design

Learning Spaces in Higher Education: Positive Outcomes by Design (Radcliffe et al. 2008) brought together the Proceedings of the Next Generation Learning Spaces 2008 Colloquium which was held at the University of Queensland. Within this publication, Radcliffe (2008) proposed the Pedagogy-Space-Technology (PST) framework for designing and evaluating learning spaces. An outline of this methodological framework is shown in Fig. 2 (above).

Radcliffe (2008, p. 11) suggested that there was "a nexus between pedagogy, technology and the design of the learning space" and proposed that the PST framework was useful for not only guiding design but also for the "POE of either discrete learning environments (e.g. individual rooms) or networks of places (e.g. a whole campus)" (Radcliffe 2008, p. 11).

The PST framework informed the evaluation of a number of the learning environment projects featured in the Proceedings, with varying degrees of success (Powell 2008). Powell identified relatively few studies that made clear linkages between pedagogical goals and the outcomes of evaluation and suggested that evaluation should focus more strongly on the types of teaching and learning activities that were observed to take place:

The primary evaluation, therefore, is to determine whether or not such behaviours are observed and which aspects of the space and technology are seen to enable, encourage and empower these types of teaching and learning activities. (p. 29)

Powell (2008, p. 29) also suggested that "the task of determining whether the pedagogy improves student learning outcomes [should be] left to a wider, possibly whole-ofinstitution based evaluation" and warned that:

Learning outcomes are clearly dependant on a significant number of variables beyond space and the task of evaluating space with respect to these outcomes when 
so many other contributing factors typically remain uncontrolled is difficult indeed.

(p. 29)

Powell (2008, p. 30) suggested that the projects featured in Radcliffe et al. (2008) provided clear evidence that universities were experimenting with different types of learning environments. He concluded that the evaluation of these innovative spaces was "an essential part of the cycle of continuous improvement in space design" (p. 30). Furthermore, he suggested that the results of evaluations should be shared across institutions to ensure that the lessons learned were used to inform future projects and that costly mistakes were not repeated.

Finally, Powell commented on the usefulness of various data collection methods. He promoted the use of observational techniques in particular, including direct observation using video footage, which he suggested can uncover unexpected patterns of use. He also recommended user surveys, including web-based questionnaires, structured interviews and focus groups.

A study of effective models and practices for technology-supported physical learning spaces (JELS)

A JISC report entitled A Study of Effective Models and Practices for Technology Supported Physical Learning Spaces (JELS) (Pearshouse et al. 2009) provided a conceptual framework for the evaluation of learning environments in higher education (see Table 4 below). This framework was intended to offer a "common vocabulary for evaluation, based around the interplay of five key factors: intentions, context, practice, designs and procedures" (Pearshouse et al. 2009, p. 4).

This report was informed by Comber and Wall's (2001) conclusion that tools were needed to investigate interactions between users and spaces (including claims made about improved spaces leading to improved learning). Furthermore, the report was informed by the Scottish Funding Council's (SFC 2006) suggestion that evaluation of the space/learning nexus using cause-and-effect models was unlikely to be useful as it was difficult to separate the effects of space from other factors that can influence learning, as well as Temple's (2007) assertion that the role of space in higher education was not well understood and further studies into evaluation methodologies were required.

The reports' evaluation framework was intended to prompt new and more insightful evaluations, as well as to assist users to identify existing patterns within current evaluation studies. Pearshouse et al. (2009) suggested, however, that the framework needed to be "extended, tested and validated with 'live' cases in order to prove its utility" (p. 4). A key conclusion arising from the Pearshouse et al. (2009) report was:

Currently, evaluators do not appear to focus strongly on the relationship between the learning activities occurring within a space, and the learning processes or measureable outcomes associated with these activities. (p. 12)

Pearshouse et al. (2009) highlighted a number of issues that require further investigation: more attention to the relationship between space and 'pedagogic performance'; more qualitative and deep research into the relationship between pedagogy and the design of learning environments; and finding ways of separating the influence of learning environments from other factors that can influence learning. In conclusion, the report identified "a need for the educational sector as a whole to reconsider how to evaluate physical learning 
Table 4 A conceptual framework for the evaluation of learning spaces (Pearshouse et al. 2009, p. 21)

\begin{tabular}{|l|}
\multicolumn{1}{c|}{ Why? } \\
\hline \multicolumn{1}{|c|}{ Intentions } \\
\hline Purpose \\
\hline Users \\
\hline Policymakers \\
\hline Policy \\
\hline
\end{tabular}

\begin{tabular}{|l|}
\multicolumn{1}{c|}{ Chat? } \\
\hline \multicolumn{1}{|c|}{ Context } \\
\hline Interactions \\
\hline Design gestures \\
\hline Curriculum \\
Maths \\
ICT \\
$\ldots$ \\
Non-specific \\
\hline Process \\
Scripted \\
Open \\
\hline
\end{tabular}

How?

\begin{tabular}{|l|}
\hline \multicolumn{1}{|c|}{ Practice } \\
\hline Occupancy \\
\hline Interactions \\
\hline Academic Contract \\
\hline Effectiveness \\
Participation \\
Processes \\
Products \\
Physicality \\
\hline Users \\
Culture \\
Learning styles \\
Affective conditions \\
Effective conditions \\
\hline Ecology \\
\hline
\end{tabular}

\begin{tabular}{|l|}
\hline \multicolumn{1}{|c|}{ Procedures } \\
\hline Timescale \\
Longitudinal \\
Quick gain \\
\hline Initiated \\
Internal \\
External \\
\hline Conducted \\
Internal \\
External \\
\hline Feedback \\
Summative \\
Formative \\
\hline Measurement Methods \\
Quantitative \\
Qualitative \\
\hline Research Methods \\
Practitioner research \\
Academic research \\
Service level evaluation \\
\hline Operation \\
Technical \\
Human \\
Top-down \\
Bottom-up \\
\hline Tracking \\
Use of space \\
Journey of learner \\
\hline Tools \\
\hline Framework \\
\hline Stages \\
Consultation \\
Pre-commission \\
Post-commission \\
Ongoing \\
\hline Baseline \\
Pre-commission \\
Comparison \\
\hline Reporting \\
\hline \\
\end{tabular}

\begin{tabular}{|l|}
\hline \multicolumn{1}{|c|}{ Designs } \\
\hline Taxonomic \\
Entrances \\
Teaching spaces \\
Learner Centres \\
\hline Use \\
Open \\
Closed \\
\hline Technology \\
Mobile \\
Connected \\
Visual \\
Supportive \\
Specialist \\
\hline Surfaces \\
Reconfigurable \\
Fixed \\
Learner Created \\
\hline Infrastructural \\
\hline
\end{tabular}

Reporting

spaces, so as to more clearly assess how they satisfy design intentions and teaching and learning needs" (Pearshouse et al. 2009, p. 4).

A comprehensive learning space evaluation model

The final report of the Australian Learning and Teaching Council project entitled A Comprehensive Learning Space Evaluation Model (Lee and Tan 2011) identified the field of learning environment evaluation in higher education as immature. The report also concluded that, because evaluations of learning environments in higher education were highly contextual, "a single model cannot provide the comprehensive basis for all evaluations" (Lee and Tan 2011, p. 4). The report went further to suggest: 
There are complex evaluation variables such as types and purposes of spaces, degrees and location of ownership, resourcing and scheduling constraints, access to participants, purposes and audiences. In each context, any evaluation model needs to be developed or adapted in order to meet the specific purposes, questions and participants, and resources, involved. (p. 11)

This 2-year research project was founded on the premise that "evaluations of learning spaces have been limited in depth, rigour and theoretical grounding" (Lee and Tan 2011, p. 3). In response, the projects' participants developed a 'baseline development model' of learning environments that identified three key stages when a building might be evaluated during its lifecycle - design, build, and occupation (see Fig. 3). This model had much in common with the BPE model put forward by Preiser and Vischer (2005), in that it identified a cyclical process of evaluation with a number of stages when evaluation might occur and promoted the notion of 'lessons learned' being fed-forward into subsequent projects.

The research project also investigated a variety of data-collection methods. In addition to "typical survey methods" (Lee and Tan 2011, p. 10), the report suggested that researchers were "seeking creative methods to gather data that provide[d] the best fit for the questions at hand" (Lee and Tan 2011, p. 10). Some of the 'creative methods' that were indentified included observational studies, video and protocol studies, diaries, movement tracking and group activities. The report suggested that, although the use of diverse methods might support data collection that could lead to new understandings about the learning/space nexus, this might also be problematic because few tools were likely to be used in more than one context, or tested in multiple evaluations over time (Lee and Tan 2011).

In conclusion, the report suggested that more longitudinal or comparative studies were required across development stages within and across projects, that more studies should be conducted to identify the relationship between learning environments and behaviour, and that proxies for student learning were required (Lee and Tan 2011). Finally, the report identified a number of challenges currently facing learning environment design and evaluation. These included (Lee and Tan 2011, p. 2):

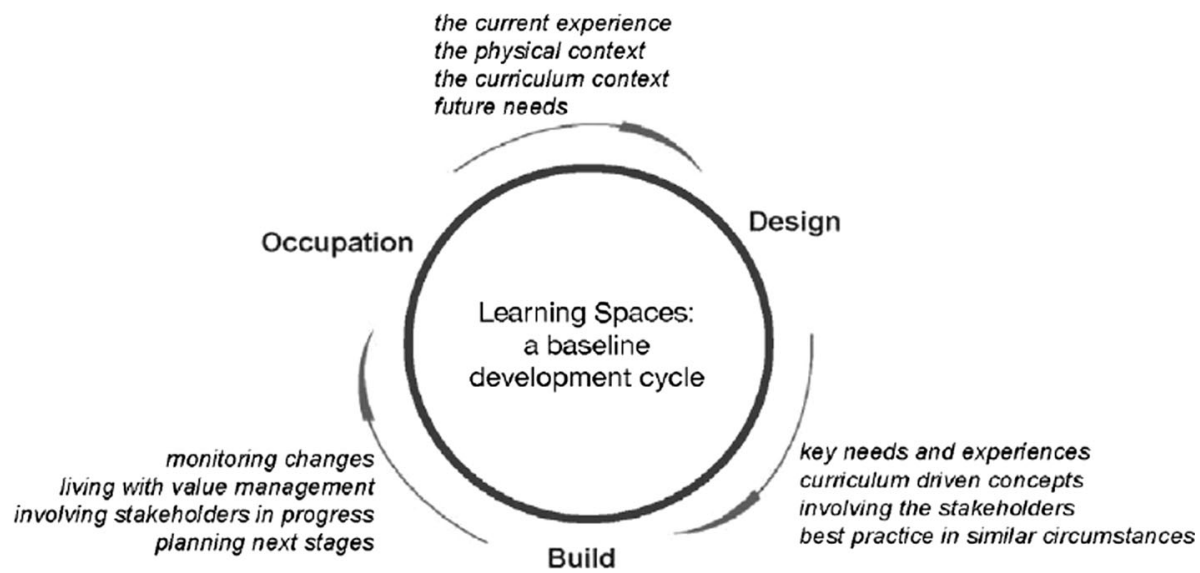

Fig. 3 The baseline development model (Lee and Tan 2011, p. 5) 
... a lack of resourcing dedicated to comprehensive evaluations; sensitivity of evaluation processes and findings; a tendency to present spaces positively and without contextual information; limitations in understanding about the purpose and value of evaluation; limiting assumptions about the potential for input from a variety of stakeholders; and the complex nature of evaluation itself.

\section{Learning environment evaluation in schools}

In this section, a sample of tools that have been used to evaluate school learning environments are critically reviewed. These tools were chosen based on their relatively rigorous approach to learning environment evaluation. The development of tools for learning environment evaluation appears to be more prevalent in this sector than in higher education. The majority of the tools reviewed below were created during the 2000s, with the exception of a tool created in 1978 by the California Department of Education. A comparative table has been included below (see Table 1) that summarises the methodologies, methods and timeframe relative to the building lifecycle, section headings and the number of questions/statements contained in these tools.

It should be noted that a number of the tools reviewed were developed in response to periods of intense school infrastructure development. For example, the Design Quality Indicator for Schools (DQIfS) tool was created in response to the UK Building Schools for the Future (BSF) program. This program was expected to fund the rebuilding or renewal of every secondary school in England by 2020 (CABE 2006) prior to the program being cancelled in 2010 following the global financial crisis.

Facilities performance profile: an instrument to evaluate school facilities

The facilities performance profile: an instrument to evaluate school facilities was developed in 1978 by the California Department of Education to "inform architects and school administrators of performance standards for new school construction" (CDE 1978, p. 1). This tool focuses on 10 categories-planning, finance, site, space, light, heat and air, sound, aesthetics, equipment and maintenance - and was designed to evaluate both preliminary designs and existing schools. The tool required evaluators (not specified) to rate their responses to a series of questions associated with each of the categories according to a given criteria. Subsequently, these values were displayed using the profile rating chart shown below (see Fig. 4). This approach supported evaluation of the planning, programming, design and construction stages of the building delivery cycle. Consequently it had qualities in keeping with the BPE model put forward by Preiser and Vischer (2005). However, it did not evaluate the appropriateness of the design(s) for pedagogical activities or take into account user perspectives or experiences.

Sanoff's multiple evaluation tools

Sanoff (2001) suggested that the evaluation of educational facilities should involve the "systematic assessment of environmental performance relative to defined objectives and requirements" (p. 6). In the School Building Assessment Manual, he presents a variety of evaluation tools that he describes as "a collection of survey and discussion tools that will encourage school administrators, teachers, students, and parents to discover and reflect 


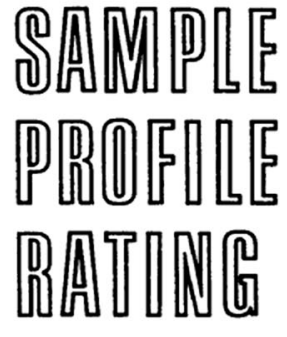

$\begin{aligned} 10 & \text { Excellent } \\ 8-9 & \text { Good } \\ 6-7 & \text { Average } \\ 4-5 & \text { Poor } \\ 0-3 & \text { Not Acceptable }\end{aligned}$

Fig. 4 Sample profile rating. The facilities performance profile: an instrument to evaluate school facilities (CDE 1978, p. 2)

upon the physical features of school buildings ... to identify what works and what does not work" (p. 1).

Sanoff's tools were intended to complement other data-collection methods, rather than fulfill building evaluation data-collection requirements by themselves. He suggested that the evaluation of learning environments required the collection of information via questionnaires, walk-throughs and interviews and concluded that the "success or failure of a POE depend[ed] on the skill with which a researcher select[ed] and use[d] informationgathering methods" (p. 7).

The tools that Sanoff outlined supported both formative and summative forms of evaluation. His formative tools were designed to aid the planning and design process, while the summative tools were intended to support the evaluation of facilities once built and in use. His formative tools included the Classroom Arrangement Rating Scale (see Fig. 5), Wish Poem, and a series of photograph elicitation questionnaires (see example in Fig. 6). His summative tools included the Six Factor School Building Checklist: A Walking Tour (see Fig. 7 below), School Building Observation Form, School Building Rating Scale, Classroom Environment Ratings and the Space Assessment Worksheet. Further details regarding a selection of these tools are included in Table 5. 
Sanoff (2001) also outlined a process that he termed Relating Objectives to Learning to Education (ROLE). ROLE was intended to support pedagogical transformation by involving teachers, students, parents, administrators and designers in "exploring aspects of the school environment by considering alternative approaches to teaching and learning" ( $\mathrm{p}$. 23).

Sanoff's contribution to the field of learning environment evaluation shifted the focus of building evaluation in education towards interest in evaluating how learning environments could be used to support pedagogical activities.

\section{Design Quality Indicators for Schools (DQIfS)}

Design Quality Indicators for Schools (DQIfS) was developed in 2005 by the Construction Industry Council and the Department for Education and Skills in the UK to evaluate the quality of both primary and secondary school buildings (CABE 2005; CIC 2011; OECD 2006). This tool was based on the earlier Design Quality Indicators (DQI), which was developed in 2002 to evaluate commercial and domestic buildings (CIC 2011).

It was designed to assist a range of stakeholders including teachers, parents, school governors, students, community members, local authority clients and building professionals to "achieve design excellence in new or refurbished buildings and grounds" (OECD 2006, p. 1), DQIfS was framed around three broad criteria: functionality-the way the building is designed to be used as a school; build quality - the performance of the building fabric; and impact-its ability to create a sense of place and have an uplifting effect on the local community and environment (CABE 2006). Details regarding the subsections within these broad criteria are provided in Table 5 (below).

DQIfS is composed of 111 statements about school design. Examples of these statements from the 'Functionality—space' sub-section include: "teaching spaces should be adequate and appropriate for the curriculum and organisation of the school" and "there should be adequate and appropriately located storage space" (CABE 2005, p. 27). In keeping with Preiser and Vischer's (2005) BPE framework, DQIfS can be used at various stages in the building delivery cycle, including during initial (consultation), mid-design, ready-for-occupation and in-use stages (OECD 2006). Consequently, DQIfS can be used as both a formative and summative evaluation tool, which is designed to be supported by a trained DQI facilitator.

The DQIfS tool provides a rigorous evaluation model that supports reflection on the attributes of functionality, build quality and impact, as defined by the tool. However, it neglects to deal with the appropriateness of learning environments for pedagogical activities. As a result, it does not evaluate the potential impact of design on opportunities for varied approaches to teaching and learning, or make connections between educational philosophy, learning activities and the design of the built environment.

\section{Educational Facilities Effectiveness Instrument (EFEI)}

The Educational Facilities Effectiveness Instrument (EFEI) was developed in 2005 by Fielding Nair International. This web-based instrument was intended to provide "a detailed measure of a school building and campus' effectiveness to support twenty-first century teaching and learning modalities" (FNI 2011). Based on the values and beliefs held by its developers about school design, EFEI was intended to support school communities "closely monitor the efficacy of solutions throughout the process of visioning, planning, designing, constructing, occupying, maintaining and refurbishing a school building and 

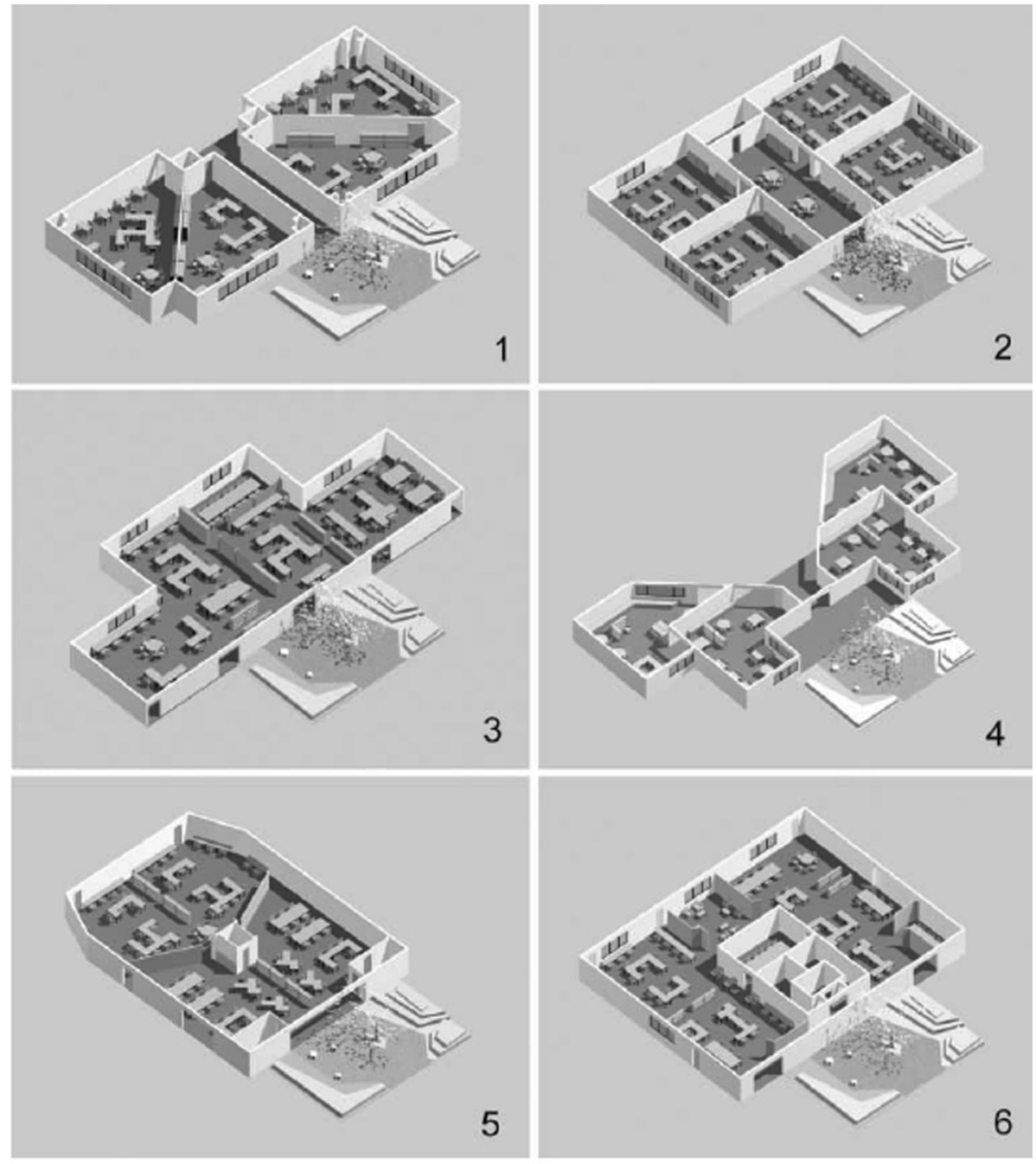

Please select the best classroom arrangement that would satisfy each of the following statements:

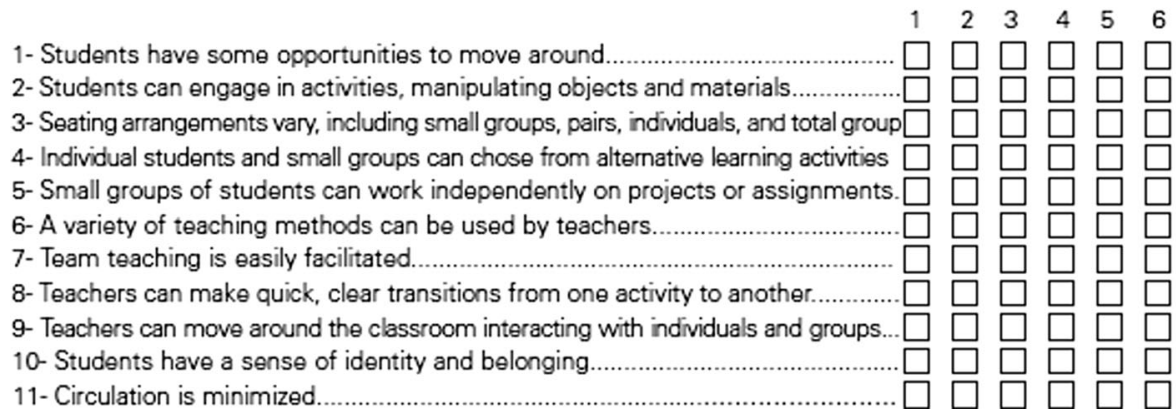

Fig. 5 Classroom Arrangement Rating Scale (Sanoff 2001, p. 30) 


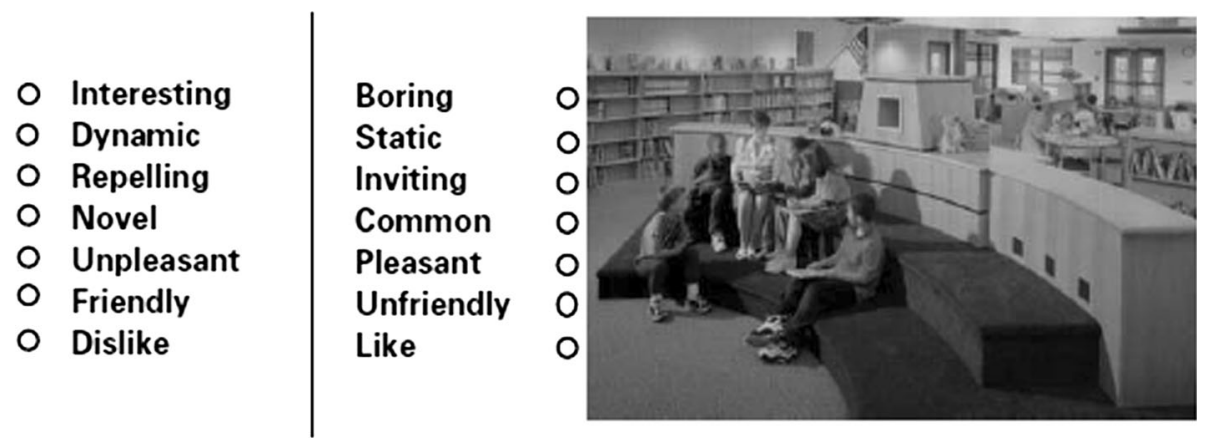

Fig. 6 Sample from Informal Social Rating Scale (photo elicitation questionnaire) (Sanoff 2001, 18)

The six factor school building assessment is an approach that allows you to focus on six key elements of building assessment -.- context, massing, interface, wayfinding, social space and comfort. By using a series of checklist questions and a numerical rating scale you can assign a score to each factor being assessed.

On each item below, rate your satisfaction with the overall quality of the building design where:

\begin{tabular}{|c|c|c|c|}
\hline $\begin{array}{l}\text { VU=Very U=Unsatisfactory } \\
\text { Unsatisfactory }\end{array}$ & $\begin{array}{l}\text { SU=Somewhat } \\
\text { Unsatisfactory }\end{array}$ & $\mathbf{N}=$ Neither & $\begin{array}{c}\text { SS=Somewhat } \\
\text { Satisfactory }\end{array}$ \\
\hline
\end{tabular}

Factor 1 - Context: The school building's setting

1- Does the building suit the pattern of the surrounding streets?

2- Does the scale of the building suit the site it sits upon?

3- Does the scale of the building suit the scale of the surrounding buildings?.

4- Do the public and private areas relate well to one another?

5- Do the land uses adjacent to the building seem to fit harmoniously with the building?

6- Does the school building and its intended use fit well with the type and uses of adjacent buildings?....

7- Does the appearance of the building fit in well with the buildings surrounding it?

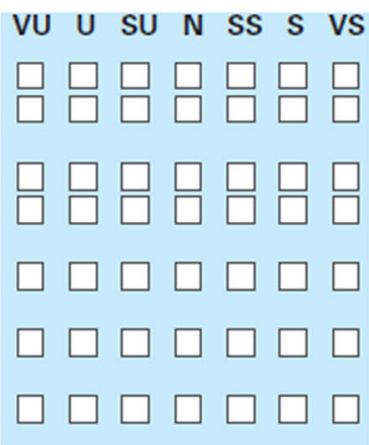

Write any comments or concerns that you may have about the way the building suits or fails to suit the context of the surrounding area.

Fig. 7 Sample from Six Factor School Building Checklist: A Walking Tour (Sanoff 2001, p. 10)

campus" (FNI 2011). This could be overstating the application of the tool, because EFEI is effectively a 180 question summative walkthrough questionnaire. However, like Design Quality Indicators for Schools (DQIfS) (reviewed above), it could be used formatively during the design process to highlight a variety of design issues that stakeholders might wish to consider further.

Although some links between educational philosophy, learning activities and the design of the built environment are evident, these links are closely correlated with the values and beliefs of the tools' developers. EFEI does not capture information about the educational philosophy or desired learning activities of participating schools and subsequently this 


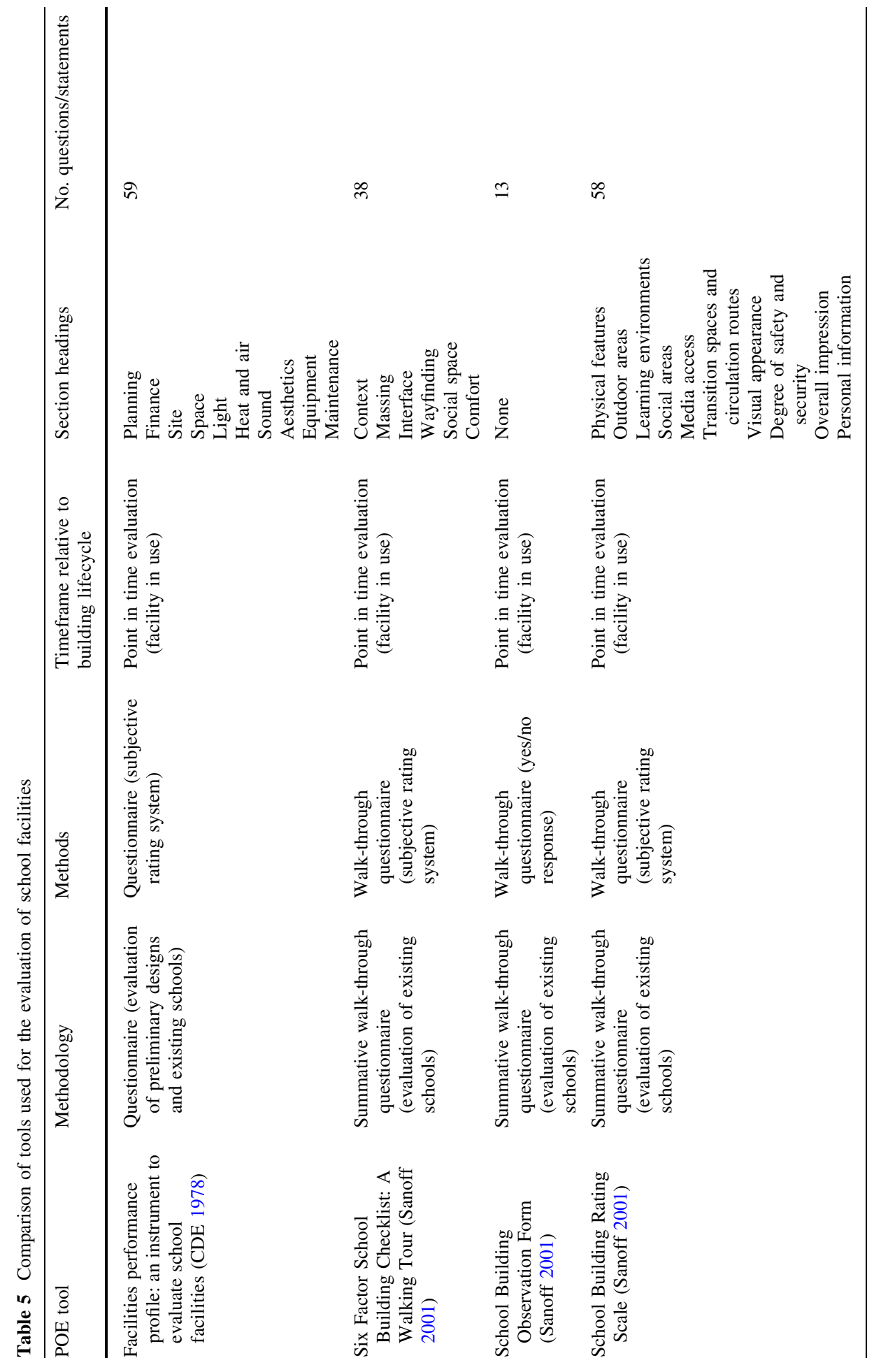




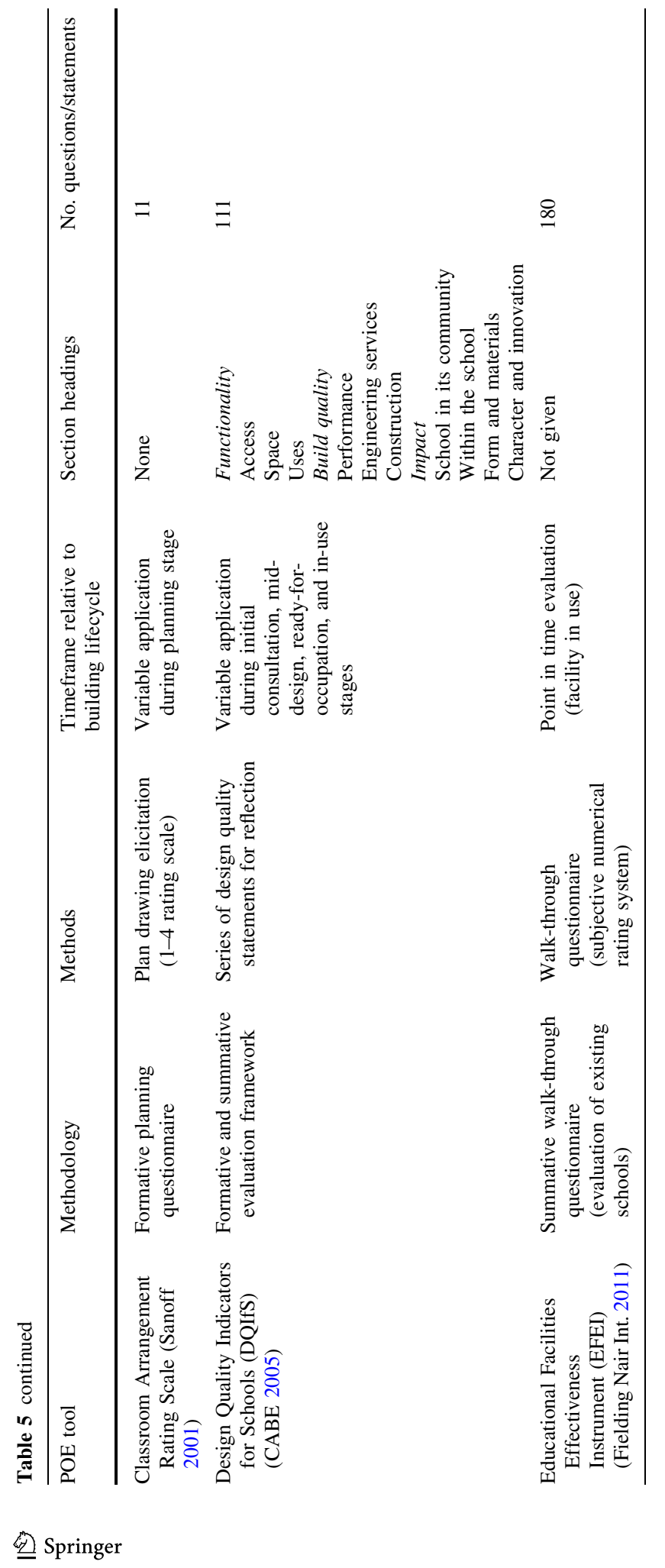




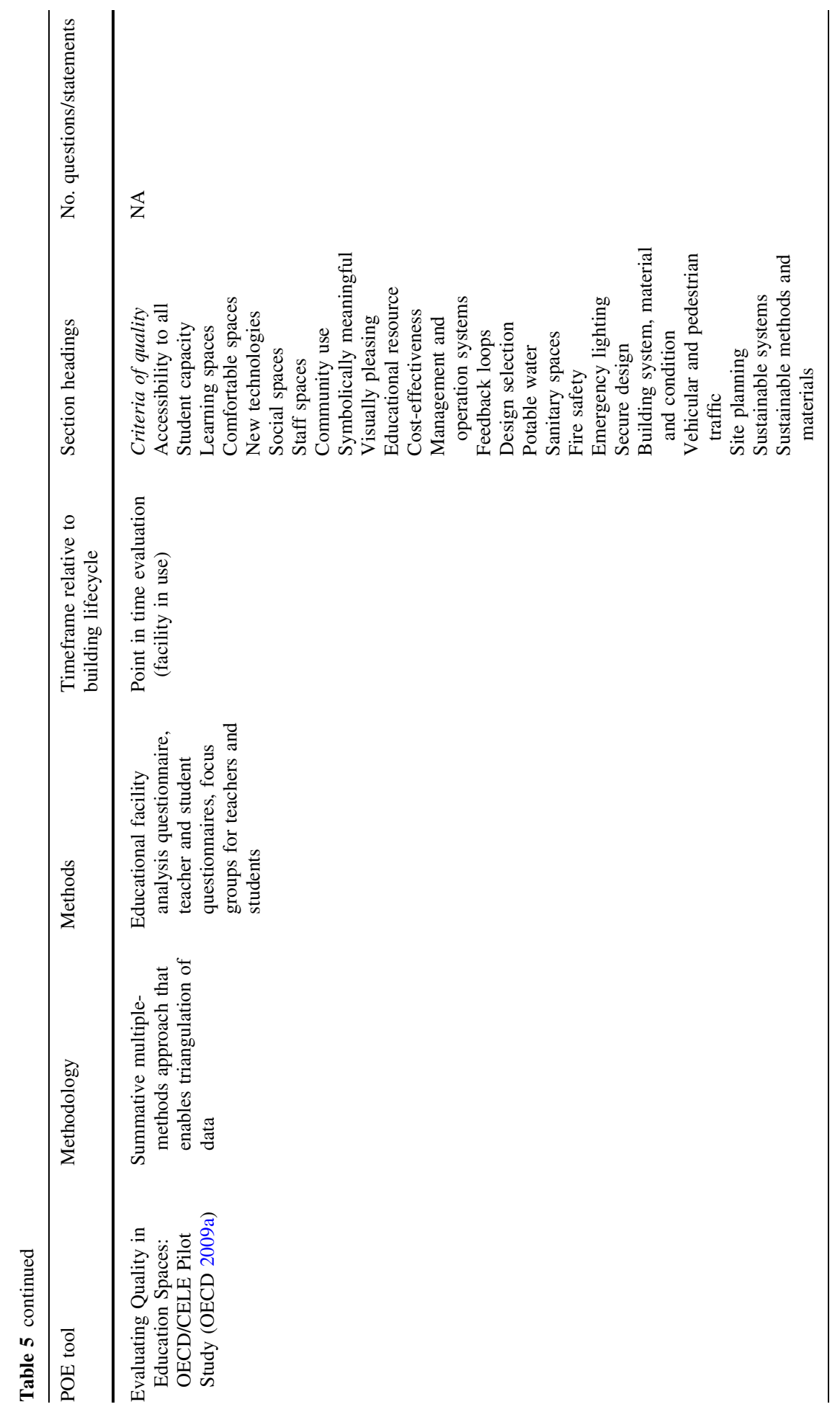




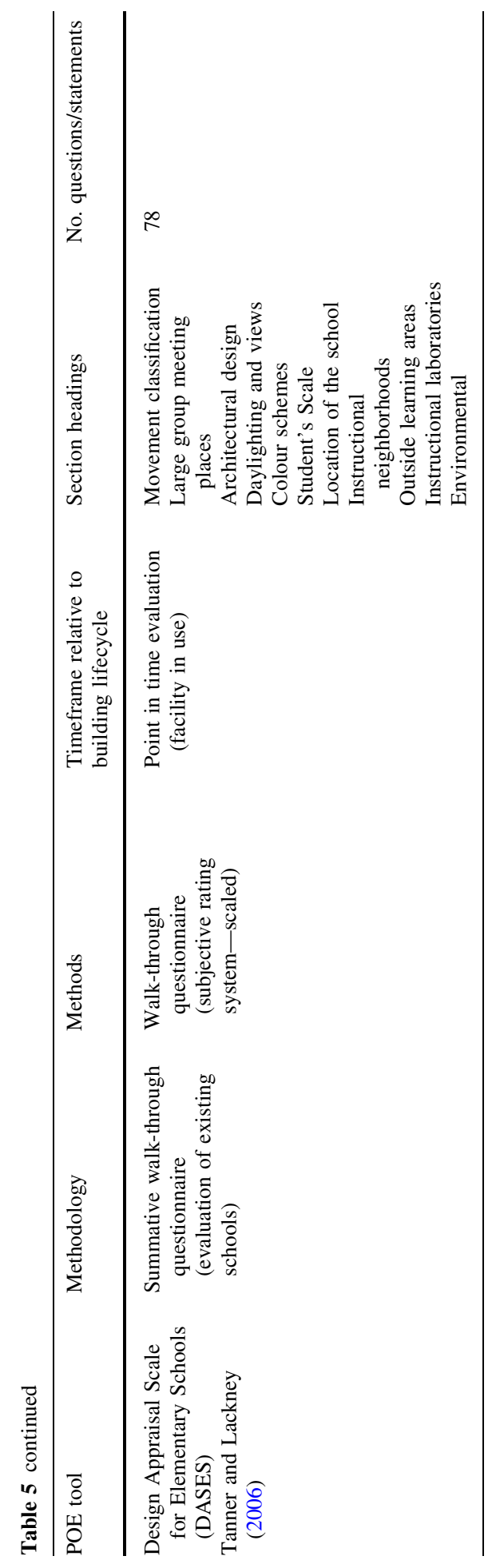


information is not integrated into the evaluation process to determine how well learning environments align with, or support, desired teaching and learning activities.

\section{Evaluating quality in education spaces: OECD/CELE pilot study}

In 2005, the Organisation for Economic Co-operation and Development (OECD) began work on a pilot project concerned with the evaluation of school learning environments. This project was conducted by the Centre for Effective Learning Environments (CELE) and was supported by OECD member nations of Brazil, Greece, Mexico, New Zealand, Portugal and UK (England and Scotland). The state of Victoria, Australia also participated as an affiliate member. The overarching objective of the project was to "assist education authorities, schools and others to maximise the use of and investment in educational spaces" (OECD 2009a, p. 4). Additional objectives were to "develop user-friendly, costeffective tools and data gathering strategies; identify good practices and 'lessons learned' in participating countries; and explore the contextual issues and constraints to improving quality in educational spaces" (OECD 2009b, p. 2).

An important issue raised by this project concerned how to define quality in contemporary educational environments. In response to this issue, CELE developed the Organising Framework on Evaluating Quality in Educational Spaces, which is a conceptual framework that defined quality for the purposes of the study (see outline in Table 5). CELE framed their 'criteria of quality' around a set of principles that they believed linked educational policy and educational facilities (OECD 2009a). These principles included: "increase access and equity to education; improve educational effectiveness and promote acquisition of key competencies; and optimize building performance, operation and costeffectiveness" (OECD 2009a, pp. 37-38).

In order to evaluate schools against their 'criteria of quality', CELE employed a mixedmethods approach to data collection. The methods that were employed included an educational facility analysis questionnaire, student and teaching staff questionnaires, and focus-group sessions for both teachers and students. Data collection was conducted by national coordinators and research teams, teaching staff, students, school principals and others. To account for varied perceptions regarding what constituted quality in learning environments between participating nations, each nation was required to complete a priority-rating exercise for the OECD quality performance objectives.

The CELE approach to school facility evaluation constituted a rigorous approach. However, the 'criteria of quality' appeared to suggest that learning environments are containers within which learning activities occur, rather than 'built pedagogies' (Monahan 2000, 2002, 2005) that could influence teaching and learning practices, activities and behaviours. CELE's evaluation approach appeared not to gather sufficient information regarding the particular educational philosophies and objectives of each participating school: objectives that could be used to reference how well learning environments aligned with desired approaches to teaching and learning.

\section{Design Appraisal Scale for elementary schools}

In Educational Facilities Planning, Tanner and Lackney (2006) included a tool for the evaluation of elementary (primary) schools, the Design Appraisal Scale for Elementary Schools. This walk-through questionnaire provided occupants with a systematised approach for reflecting on the attributes of their facilities. The questionnaire focused on the following categories: movement classifications, large group meeting places, architectural 
design, daylighting and views, colour schemes, student's scale, location of the school, instructional neighborhoods, outside learning areas, instructional laboratories and environmental components.

Tanner and Lackney recognised the limitations of this summative approach to evaluation. They concluded that summative assessments of school facilities were "performed too late to make a difference in major aspects of design" (2006, p. 66) and subsequently recommended that formative evaluations were more valuable-especially those that took into account the planning, programming, design, construction and management of a facility and related it to student learning. However, they identified a dearth of information related to formative evaluations of educational architecture.

\section{Discussion and conclusions}

The first section of this literature review provided a historical perspective on the field of POE. It charted the development of POE for non-domestic buildings since the 1960s, when the first systematic building evaluations were conducted. This section outlined various definitions of POE, discussed why POEs can be beneficial, detailed the recent evolution of POE into the broader evaluative framework of BPE (Preiser and Vischer 2005), and discussed the methodologies and methods that have been employed to conduct POEs on non-domestic buildings.

Subsequently, a review of approaches to the evaluation of educational buildings/ learning environments in higher education and school settings revealed that the focus of evaluation in education has begun to shift in keeping with recent developments in learning environment design. The creation of innovative learning environments in higher education settings in particular appears to have encouraged researchers to search for novel evaluation methodologies and methods that can be used to assess the effectiveness of educational facilities in supporting the learning process. This renewed interest in evaluation at the intersection of the physical and the social represents a return to the origins of POE in environmental psychology. It also supports Preiser and Nasar's (2008) view that a new perspective on building evaluation is currently being developed that favours 'bottom up' approaches to evaluation, which value the opinions of the user.

This literature review clearly indicates that approaches to evaluations that attempt to assess the effectiveness of physical learning environments in supporting pedagogical activities are in their infancy and require further development. As indicated by Radcliffe (2008), Powell (2008), Pearshouse et al. (2009) and Lee and Tan (2011), more studies are required in order to develop rigorous methodologies and methods that can be confidently employed to assess the effectiveness of physical learning environments in supporting desired teaching and learning practices, activities and behaviours. Based on recent research conducted in the higher education sector, evaluation tools/approaches appear to be required that can be easily modified to accommodate the specific physical settings and social contexts within which they are to be applied-as well as the various interests of those commissioning the evaluation.

Such research could profit from an interdisciplinary approach that involves people from a variety of backgrounds, including but not limited to education, human geography, environmental psychology and architecture. As different epistemologies tend to be favoured by different disciplines, an interdisciplinary approach might provide the developmental space needed to generate new knowledge regarding learning environment evaluation. Eigenbrode et al. (2007) concluded that the integration of disciplines in 
interdisciplinary research can be achieved through the unified identification of problems and the sharing of research methods across disciplines. The development of new perspectives concerning learning environment evaluation might well be achieved via a process of reframing the issues and sharing 'novel' research methods.

With regard to schools, the literature reviewed demonstrated that a number of tools have been developed in various countries to evaluate school learning environments. The majority of these tools, however, focus predominantly on the physical features of the physical environment itself, rather than the alignment between spaces and desired educational practices, activities and behaviours. In addition, few tools seek the opinions of students, the principal users of school learning environments.

Across all educational sectors, it appears that new building evaluation methodologies are required if a deeper understanding is to be attained regarding how effectively learning environments can support the educational programs and practices of the twenty-first century. In particular, the development of formative evaluation methodologies, which could support the evaluation of educational facilities throughout their lifecycle, appears to be warranted.

These finding are in keeping with Temple's (2008, p. 229) conclusion that "further research is needed to illuminate the connections between space and institutional effectiveness". These findings are also aligned with those of Ornstien et al. (2009), who concluded that there was a need for "continuous user-informed BPEs, beginning at the earliest stages of needs assessment and conceptual design and continuing throughout the use, management and maintenance of school buildings" (p. 364), and that "user-informed assessments increase the likelihood that a given school building fulfils its intended educational purposes to the greatest degree possible" (p. 364).

Acknowledgments We would like to thank Professor Tom Kvan, Dean of Faculty of Architecture, Building and Planning at The University of Melbourne and Director of the Learning Environments Applied Research Network (LEaRN) for commissioning this literature review. In addition, we would like to thank LEaRN partners Catholic Education Office Melbourne and Karolinska Institute, for their support. We are indebted to Associate Professor Clare Newton and LEaRN Executive Officer Alan Gilmour and for their editorial advice and general support during the writing of this article.

\section{References}

Aldridge, J., Fraser, B., Bell, L., \& Dorman, J. (2012). Using a new learning environment questionnaire for reflection in teacher action research. Journal of Science Teacher Education, 23, 259-290.

Beare, H. (2000). Creating the future school. London: Routledge Falmer.

Buckley, J., Schneider, M., \& Shang, Y. (2005). Fix it and they might stay: School facility quality and teacher retention in Washington D.C. Teachers College Record, 107, 1107-1123.

CABE. (2005). Picturing school design. A visual guide to secondary school buildings and their surroundings using the Design Quality Indicator for Schools. London: Commission for Architecture and the Built Environment.

CABE. (2006). Assessing secondary school quality: Research report. London: Commission for Architecture and the Built Environment.

CDE. (1978). Facilities performance profile: An instrument to evaluate school facilities. Sacramento, CA: California Department of Education.

CERD. (2010). Learning landscapes in higher education. Lincoln: Centre for Educational Research and Development, University of Lincoln.

CIC. (2011, September). Design quality indicators for schools. London: Construction Industry Council. http://www.dqi.org.uk/website/dqiforschools/default.aspa. Accessed 12/7/11. 
Clarke, H. (2001, September). Building education: The role of the physical environment in enhancing teaching and learning. Paper presented at the British Educational Research Association annual conference, University of Leeds.

Cleveland, B. (2009). Engaging spaces: An investigation into middle school educational opportunities provided by innovative built environments: A new approach to understanding the relationship between learning and space. The International Journal of Learning, 16, 385-397.

Cleveland, B. (2011). Engaging spaces: Innovative learning environments, pedagogies and student engagement in the middle years of school. Unpublished PhD thesis, The University of Melbourne, Melbourne.

Cohen, R., Standeven, M., Bordass, W., \& Leaman, A. (2001). Assessing building performance in use 1: the Probe process. Building Research \& Information, 29(2), 85-102.

Comber, C., \& Wall, D. (2001). The classroom environment: A framework for learning. In C. Paechter, R. Edwards, R. Harrison, \& T. Twining (Eds.), Learning, space and identity (pp. 87-101). London: Paul Chapman Publishing.

Cooper, I. (2001). Post-occupancy evaluation-Where are you? Building Research \& Information, 29, $158-163$.

Dewey, J. (1966). Experience and education. New York: Collier Books.

Dewey, J. (1971). The child and the curriculum. The school and society (11th ed.). Chicago: The University of Chicago Press.

Dudek, M. (2008). Schools and kindergartens-A design manual. Berlin: Birhauser.

Edwards, R., \& Clarke, J. (2002). Flexible learning, spatiality and identity. Studies in Continuing Education, 24, 153-165.

Eigenbrode, S. D., O’Rourke, M., Wulfhorst, J. D., Althoff, D. M., Goldberg, C. S., Merrill, K., et al. (2007). Employing philosophical dialogue in collaborative science. BioScience, 57, 55-64.

Fisher, K. (2002). Schools as 'prisons of learning' or, as a 'pedagogy of architectural encounters': A manifesto for a critical psychological spatiality of learning. Unpublished PhD thesis, Flinders University of South Australia, Adelaide.

Fisher, K. (2004). Revoicing classrooms: A spatial manifesto. Forum, 46(1), 36-38.

Fisher, K. (2005). Linking pedagogy and space: Planning principles for Victorian schools based on the principles of teaching and learning. www.eduweb.vic.gov.au/edulibrary/public/assetman/bf/Linking Pedagogy_and_Space.pdf. Accessed 25/8/11.

Flyvbjerg, B. (1998). Habermas and Foucault: Thinkers for civil society? The British Journal of Sociology, 49, 210-233.

FNI. (2011). Educational Facilities Effectiveness Instrument. Lutz, FL: Fielding Nair International. http:// goodschooldesign.com/Default.aspx. Accessed 6/6/11.

Fraser, B. J., \& Walberg, H. J. (Eds.). (1991). Educational environments: Evaluation, antecedents, and consequences. Oxford: Pergamon Press.

Friere, P. (1970). Pedagogy of the oppressed. New York: Herder and Herder.

Hadjri, K., \& Crosier, C. (2008). Post-occupancy evaluation: Purpose, benefits and barriers. Facilities, 27(1/ 2), 21-33.

Hartnell-Young, E. (2006). Teachers' roles and professional learning in communities of practice supported by technology in schools. Journal of Technology and Teacher Education, 14, 461-480.

HEFCE. (2006). Guide to post occupancy evaluation. Bristol: Higher Education Funding Council for England.

Heppell, S., Chapman, C., Millwood, R., Constable, M., \& Furness, J. (2004). Building learning futures. Building futures. www.buildingfutures.org.uk. Accessed 4/8/08.

Higgins, S., Hall, E., Wall, K., Wooler, P., \& McCaughey, C. (2005). The impact of school environments: A literature review. London: The Design Council. www.design-council.org.uk. Accessed 5/4/10.

Hirst, P. (2005). Foucault and architecture. In P. Hirst (Ed.), Space and power: Politics, war and architecture (pp. 155-178). Cambridge: Polity.

Hunley, S., \& Schaller, M. (2006). Assessing learning spaces. In D. Oblinger (Ed.), Learning spaces (pp. 1-11). Washington, DC: Educause.

Jamieson, P., Dane, J., \& Lippman, P. C. (2005). Moving beyond the classroom: Accommodating the changing pedagogy of higher education. Paper presented at the Forum of the Australian Association for Institutional Research. Retrieved from http://www.aair.org.au/pages/forum-2005. Accessed 11/8/ 11.

JISC. (2006). Designing spaces for effective learning: A guide to 21st century learning space design. Joint Information Systems Committee Development Group. www.jisc.ac.uk/media/documents/publications/ learningspaces.pdf. Accessed 31/5/11.

Joseph, J. (2003). Social theory. Edinburgh: Edinburgh University Press. 
Lackney, J. A. (1999). Assessing school facilities for learning/Assessing the impact of the physical environment on the educational process. Paper presented at the Urban Educational Facilities for the 21st Century: CEFPI North East Chapter First Annual Conference, New Jersey Institute of Technology, Newark, NJ.

Lave, J., \& Wenger, E. (1991). Situated learning: Legitimate peripheral participation. Cambridge: Cambridge University Press.

Leaman, A., Stevenson, F., \& Bordass, B. (2010). Building evaluation: Practice and principles. Building Research \& Information, 38, 564-577.

Lee, N., \& Tan, S. (2011). A comprehensive learning space evaluation model. Strawberry Hills, NSW: Australian Teaching and Learning Council.

Lefebvre, H. (1991). The production of space. Oxford: Blackwell.

Lippman, P. C. (2007). Developing a theoretical approach for the design of learning environments. Paper presented at the Connected: International Conference of Design Education, University of New South Wales, Australia.

Massey, D. (1999). Power geometrics and the politics of space-time: Hetter Lecture. Heidelberg: University of Heidelberg.

Massey, D. (2005). For space. London: Sage Publications.

McGregor, J. (2004a). Editorial. Forum, 46(1), 2-5.

McGregor, J. (2004b). Spatiality and the place of the material in schools. Pedagogy, Culture \& Society, 12, 347-372.

McGregor, J. (2004c). Space, power and the classroom. Forum, 46(1), 13-18.

McLaren, P. (2007). Life in schools: An introduction to critical pedagogy in the foundations of education. London: Pearson Education.

Monahan, T. (2000). Built pedagogies and technology practices: Designing for participatory learning. Paper presented at the Participatory Design Conference, Palo Alto, CA.

Monahan, T. (2002). Flexible space and built pedagogy: Emerging IT embodiments. Inventio, 4(1), 1-19.

Monahan, T. (2005). Globalization, technological change, and public education. New York: Routledge.

Moos, R. H. (1979). Evaluating educational environments. San Francisco: Jossey-Bass Publishers.

Moos, R. H. (1987). Person-environment congruence in work, school, and health care settings. Journal of Vocational Behavior, 31, 231-247.

Newmann, F. (1992). Higher-order thinking and prospects for classroom thoughtfulness. In F. Newmann (Ed.), Student engagement and achievement in American secondary schools (pp. 62-91). New York: Teachers College Press.

Newton, C., \& Fisher, K. (2009). Take 8, Learning spaces: The transformation of educational environments for the 21st Century. Manuka, ACT: Australian Institute of Architects.

OECD. (2006). Design quality indicator for schools in the United Kingdom. PEB Exchange, 8, 1-3.

OECD. (2009a). OECD Centre for Effective Learning Environments (CELE, formerly PEB). International pilot study on the evaluation of quality in educational spaces (EQES), User manual. Final version. Paris: OECD.

OECD. (2009b). Evaluating quality in educational spaces: OECD/CELE pilot project. CELE Exchange, 9, $1-6$.

Ornstien, S. W., Moreira, N. S., Ono, R., Franca, A. J. G. L., \& Nogueira, R. A. M. F. (2009). Improving the quality of school facilities through building performance assessment: Educational reform and school building quality in Sao Pauol, Brazil. Journal of Educational Administration, 47, 350-367.

Pearshouse, I., Bligh, B., Brown, E., Lewthwaite, S., Graber, R., Hartnell-Young, E., et al. (2009). A study of effective models and practices for technology supported physical learning spaces (JELS). Nottingham: JISC.

Powell, D. (2008). Evaluation and the pedagogy-space-technology framework. In D. Radcliffe, W. Wilson, D. Powell, \& B. Tibbetts (Eds.), Learning spaces in higher education. Positive outcomes by design: Proceedings of the next generation learning spaces 2008 colloquium. St Lucia, QLD: The University of Queensland.

Preiser, W. F. E. (1995). Post-occupancy evaluation: How to make buildings work better. Facilities, 13(11), 19-28.

Preiser, W. (2001). The evolution of post-occupancy evaluation: Toward building performance and universal design evaluation. In J. Vischer (Ed.), Post-occupancy evaluation: A multifaceted tool for building improvement, learning from our buildings: A state-of-the-practice summary of post-occupancy evaluation. Washington, DC: National Academy Press.

Preiser, W. F. E. (2002). Toward universal design evaluation. Paper presented at the 17th conference international association for people-environment studies; culture, quality of life and globalization: Problems and challenges for the new millennium, Corunna, Spain. 
Preiser, W. F. E., \& Nasar, J. L. (2008). Assessing building performance: Its evolution from post-occupancy evaluation. International Journal of Architectural Research, 2(1), 84-99.

Preiser, W. F. E., \& Vischer, J. (2005). The evolution of building performance evaluation: An introduction. In W. Preiser \& J. Vischer (Eds.), Assessing building performance (pp. 3-14). Oxford: Elsevier Butterworth-Heinemann.

Radcliffe, D. (2008). A pedagogy-space-technology (PST) framework for designing and evaluating learning places. In D. Radcliffe, W. Wilson, D. Powell, \& B. Tibbetts (Eds.), Learning spaces in higher education: Positive outcomes by design. St Lucia, QLD: The University of Queensland.

Radcliffe, D., Wilson, W., Powell, D., \& Tibbetts, B. (Eds.). (2008). Learning spaces in higher education. Positive outcomes by design: Proceedings of the next generation learning spaces 2008 colloquium. St Lucia, QLD: The University of Queensland.

Roberts, L. W. (2008). Measuring school facility conditions: An illustration of the importance of purpose. Journal of Educational Administration, 47, 368-380.

Sanoff, H. (2001). School building assessment methods. Washington, DC: National Clearinghouse for Educational Facilities.

SFC. (2006). Spaces for learning: A review of learning spaces in further and higher education. Edinburgh: Scottish Funding Council.

Soja, E. W. (1989). Postmodern geographies: The reassertion of space in critical social theory. London: Verso.

Stevenson, K. (2007). Educational trends shaping school planning and design: 2007. Washington, DC: National Clearinghouse for Educational Facilities.

Tanner, C. K., \& Lackney, J. A. (2006). Educational facilities planning. Boston: Pearson Education.

Taylor, A. (2009). Linking architecture and education: Sustainable design for learning environments. Albuquerque: University of New Mexico Press.

Temple, P. (2007). Learning spaces for the 21st century: A review of the literature. London: London Centre for Higher Education Studies, Institute of Education, University of London.

Temple, P. (2008). Learning spaces in higher education: An under-researched topic. London Review of Education, 6, 229-241.

Turpin-Brooks, S., \& Viccars, G. (2006). The development of robust methods of post occupancy evaluation. Facilities, 24(5/6), 177-196.

Upitis, R. (2010). Raising a school: Foundations for school architecture. South Frontenac, ON: Wintergreen Studios Press.

Vischer, J. (2001). Post-occupancy evaluation: A multifaceted tool for building improvement, learning from our buildings: A state-of-the-practice summary of post-occupancy evaluation. Washington, DC: National Academy Press.

Walker, S., \& Fraser, B. (2005). Development and validation of an instrument for assessing distance education learning environments in higher education: The distance education learning environments survey (DELES). Learning Environments Research, 8, 289-308.

Wall, K., Dockrell, J., \& Peacey, N. (2008). Primary schools: The built environment (Primary Review Research Survey 6/1). Cambridge: University of Cambridge Faculty of Education.

Weinstein, C. S. (1979). The physical environment of the school: A review of the research. Review of Educational Research, 49, 577-610.

Whyte, J., \& Gann, D. M. (2001). Closing the loop between design and use: Post-occupancy evaluation. Building Research \& Information, 29, 460-462.

Zeisel, J. (2006). Inquiry by design: Environment/behavior/neuroscience in architecture, interiors, landscape, and planning. New York: W.W. Norton \& Company.

Zhang, Y., \& Barrett, P. (2010). Findings from a post-occupancy evaluation in the UK primary schools sector. Facilities, 28(13/14), 641-656.

Zimmerman, A., \& Martin, M. (2001). Post-occupancy evaluation: Benefits and barriers. Building Research \& Information, 29, 168-174.

Zimring, C. M., \& Reizenstein, J. E. (1980). Post-occupancy evaluation: An overview. Environment and Behavior, 12, 429-450. 